\title{
Reducing lactate secretion by $l d h A$ Deletion in L-glutamate- producing strain Corynebacterium glutamicum GDK-9
}

\author{
Dalong Zhang ${ }^{1,2}$, Dan Guan ${ }^{3}$, Jingbo Liang ${ }^{1,2}$, Chunqian Guo ${ }^{1,2}$, Xixian Xie ${ }^{1,2}$, \\ Chenglin Zhang ${ }^{1,2}$, Qingyang $\mathrm{Xu}^{1,2}$, Ning Chen ${ }^{1,2}$ \\ 1College of Biotechnology, Tianjin University of Science and Technology, Tianjin, P.R. China. \\ ${ }^{2}$ Key Laboratory of Industrial Microbiology, Education Ministry, Tianjin, P.R. China. \\ ${ }^{3}$ China Biothech Fermentation Industry Association, Beijing, P.R. China.
}

Submitted: March 5, 2013; Approved: March 14, 2014.

\begin{abstract}
L-lactate is one of main byproducts excreted in to the fermentation medium. To improve L-glutamate production and reduce L-lactate accumulation, L-lactate dehydrogenase-encoding gene $l d h A$ was knocked out from L-glutamate producing strain Corynebacterium glutamicum GDK-9, designated GDK-9 $\Delta l d h A$. GDK-9 $\Delta l d h A$ produced approximately $10.1 \%$ more L-glutamate than the GDK-9, and yielded lower levels of such by-products as $\alpha$-ketoglutarate, L-lactate and L-alanine. Since dissolved oxygen (DO) is one of main factors affecting L-lactate formation during L-glutamate fermentation, we investigated the effect of $l d h A$ deletion from GDK-9 under different DO conditions. Under both oxygen-deficient and high oxygen conditions, L-glutamate production by GDK-9 $\Delta l d h A$ was not higher than that of the GDK-9. However, under micro-aerobic conditions, GDK-9 $\Delta l d h A$ exhibited $11.61 \%$ higher L-glutamate and $58.50 \%$ lower L-alanine production than GDK-9. Taken together, it is demonstrated that deletion of $l d h A$ can enhance L-glutamate production and lower the unwanted by-products concentration, especially under micro-aerobic conditions.
\end{abstract}

Key words: Corynebacterium glutamicum, L-glutamate, L-lactate dehydrogenase, gene knockout, fermentation.

\section{Introduction}

L-glutamate, a widely-used flavoring agent throughout the world and a starting material for the synthesis of various chemicals, is predominately produced by Corynebacterium glutamicum (Calik et al., 2001). The current annual production of L-glutamate is approximately 2500000 tons with large increases each year. To date, several major strategies have been discovered that can induce L-glutamate overproduction, including biotin limitation, addition of antibiotics, surfactants, detergents, or cerulenin, and temperature triggering. The $\mathrm{L}$-glutamate producers are characterized by a low pentose phosphate pathway flux and low conversion of $\alpha$-ketoglutarate to oxaloacetate in the tricarboxylic acid (TCA) cycle, likely due to low activity of the $\alpha$-ketoglutarate dehydrogenase complex (Stansen et al., 2005).

In C. glutamicum, pyruvate is a branch point of glucose catabolism, since it is the portal to several metabolic pathways (Chen et al., 2009). Significantly, pyruvate can enter the TCA cycle in two ways: by condensation with $\mathrm{CO}_{2}$ to form a dicarboxylic acid, or by oxidative decarboxylation to acetyl CoA. In addition, pyruvate can be consumed in other reactions, including L-lactate and L-alanine synthesis by Lactate dehydrogenase (LDH) and transaminase (AlaT), respectively. Although the theoretical yield of L-glutamate from glucose is $81.74 \%(\mathrm{w} / \mathrm{w})$, the actual yield is much lower, due to high biomass and synthesis of by-products (Takac et al., 1998).

Oxygen supply is known to largely affect aerobic amino acid production by microorganisms, because aerobic 
microorganisms generally require sufficient oxygen concentrations to re-oxidize $\mathrm{NAD}(\mathrm{P}) \mathrm{H}_{2}$ or $\mathrm{FADH}_{2}$ and thereby generate adequate ATP for metabolism (Akashi et al., 1979). The dissolved oxygen (DO) levels largely determine the interactions between metabolic reactions and genetic regulatory mechanisms, as well as product and by-products formation during L-glutamate fermentation. For example, in addition to growth rate and protein synthesis, nutrient consumption and waste production rate are sensitive to DO levels (Zupke et al., 1995). The aerobic amino acid producing bacterium $C$. glutamicum accumulates lactate, succinate and acetate under oxygen-limited growth conditions (Dominguez et al., 1993; Toyoda et al., 2009).

In the L-glutamate fermentation process, due to the rapid growth and high cellular metabolism requirements of the bacteria, the oxygen supply is frequently insufficient and leads to L-lactate accumulation, which inhibits L-glutamate production. To meet the sufficient oxygen demand, the agitation rate in fermentation reactors is constantly increased during the glutamate production phase, adding cost to the already high-energy-consuming production process. To resolve this problem, we knocked out the L-lactic dehydrogenase encoding gene $l d h A$ from the L-glutamateproducing strain C. glutamicum GDK-9 (GDK-9). Here we investigate the effect of $l d h A$ gene deletion on the physiological characteristics and L-glutamate production of GDK-9.

\section{Materials and Methods}

\section{Strains, plasmids, media and cultivation}

All strains and plasmids used in this study are listed in Table 1. Escherichia coli was grown in LB medium at $37^{\circ} \mathrm{C}$, C. glutamicum was grown in BHI medium (Keihauer et al., 1993) at $32{ }^{\circ} \mathrm{C}$. The seed medium comprised glucose $\left(25 \mathrm{~g} \mathrm{~L}^{-1}\right), \mathrm{KH}_{2} \mathrm{PO}_{4}\left(2.2 \mathrm{~g} \mathrm{~L}^{-1}\right), \mathrm{MgSO}_{4}\left(0.9 \mathrm{~g} \mathrm{~L}^{-1}\right)$, corn steep liquor $\left(30 \mathrm{~mL} \mathrm{~L}^{-1}\right)$, soybean hydrolysate $\left(20 \mathrm{~mL} \mathrm{~L}^{-1}\right)$ and urea $\left(3 \mathrm{~g} \mathrm{~L}^{-1}\right)$. The production medium comprised glucose $\left(80 \mathrm{~g} \mathrm{~L}^{-1}\right), \mathrm{KH}_{2} \mathrm{PO}_{4}\left(2.0 \mathrm{~g} \mathrm{~L}^{-1}\right)$,
$\mathrm{MgSO}_{4} 7 \mathrm{H}_{2} \mathrm{O}\left(1.8 \mathrm{~g} \mathrm{~L}^{-1}\right), \mathrm{MnSO}_{4} \mathrm{H}_{2} \mathrm{O}\left(2.33 \mathrm{mg} \mathrm{L}^{-1}\right)$, $\mathrm{FeSO}_{4} 7 \mathrm{H}_{2} \mathrm{O}\left(2.33 \mathrm{mg} \mathrm{L}^{-1}\right), \mathrm{VB}_{1}\left(0.233 \mathrm{mg} \mathrm{L}^{-1}\right)$, corn steep liquor $\left(5 \mathrm{~mL} \mathrm{~L}^{-1}\right)$ and soybean hydrolysate $\left(10 \mathrm{~mL} \mathrm{~L}^{-1}\right)$.

\section{Construction of recombinant plasmids}

Plasmid for gene disruption in C. glutamicum was derived from pK18mobsacB. Upstream (ldhAI) and downstream (ldhAII) sequences of $l d h A$ were PCR-amplified from the genomic DNA of the L-glutamate-producing strain using the primer sets ldhA717-1 (5'-ATCGGAATTCAGGTGCCGACA CTAATGC-3') plus ldhA717-2 (5'-ACCGACGGTTTCTTTCATTTTCGATCCCACTTC CTGATTTC CC-3'), and ldhA600-1 (5'-ATCGAAAATGAAAGAAACCGTCGGTAACTTT TTGGTTTACGGGC -3') plus ldhA600-2 (5'-TCGAAGCTTGCTTCCAGACGGTTTCATC-3'), respectively. Splicing by overlap extension was used to fuse upstream $l d h A \mathrm{I}$ and downstream $l d h A \mathrm{II}$ using the primer pair ldhA717-1 and ldhA600-2. The resulting fragment was digested by Hind III and EcoR I, cloned into vector pK18mobsacB and transformed into E.coli DH5aMCR. Transformants were selected on LB agar containing $50 \mu \mathrm{g} \mathrm{mL}^{-1}$ kanamycin. The resulting recombinant vector $\mathrm{pK} 18$ mobsacB $\Delta l d h A$ was verified by DNA sequencing. The construction process of recombinant plasmid was showed in Figure 1.

\section{Construction of the recombinant strains}

The resulting plasmid $\mathrm{pK} 18$ mobsacB $\Delta l d h A$ was isolated from E. coli $\mathrm{DH} 5 \alpha \mathrm{MCR}$ and electroporated into GDK-9 (Van der Rest et al., 1999; Schäfer et al., 1994). The intact chromosomal $l d h A$ was replaced by the truncated $\Delta l d h A$ gene via homologous recombination (double crossover). Because the plasmid pK18mobsacB cannot duplicate in C. glutamicum, the recombinant strain alone could survive on the kanamycin-containing medium. The recombinants were picked up from the Petri dish and cul-

Table 1 - Strains, plasmids and primers used in this work.

\begin{tabular}{|c|c|c|}
\hline Stains/plasmids & Characters & Source \\
\hline \multicolumn{3}{|l|}{ Strains } \\
\hline \multicolumn{3}{|l|}{ E. coli } \\
\hline DH5 $\alpha$ MCR & $\mathrm{F}^{-} \varphi 80 \mathrm{dlacZ} \Delta(\mathrm{lacZYA}-\operatorname{argF}) \mathrm{U} 169$ recA1 endA1 hsdR17 $\left(\mathrm{rk}^{-} \mathrm{mk}^{+}\right)$supE44 $\lambda^{-}$thi-1 gyrA96 relA1 & [Grant et al., 1990] \\
\hline \multicolumn{3}{|l|}{ C. glutamicum } \\
\hline GDK-9 & The L-glutamate producing strain & Stored in our lab \\
\hline GDK-9 $9 l d h A$ & C. glutamicum GDK-9 with ldhA deletion & This work \\
\hline \multicolumn{3}{|l|}{ Plasmids } \\
\hline pK18mobsacB & Integration vector, $\mathrm{Km}^{\mathrm{r}}$ oriV $\mathrm{Ec}_{\mathrm{Ec}}$ oriT sacB & [Jäger et al., 1992] \\
\hline pK18mobsacB $\Delta l d h A$ & pK18mobsacB carrying the $\Delta l d h A$ & This work \\
\hline
\end{tabular}




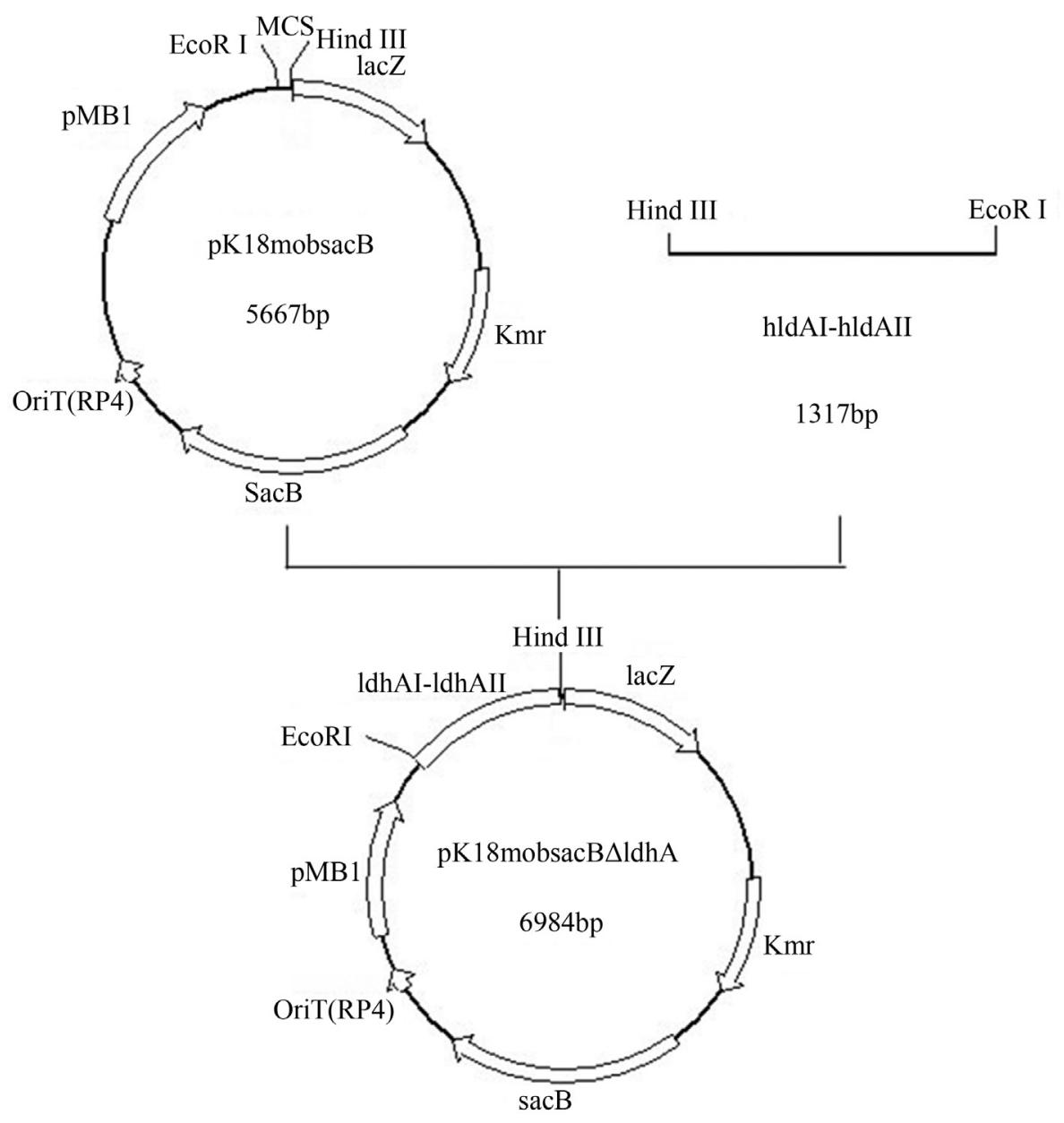

Figure 1 - The construction process of recombinant plasmid.

tured in BHIS liquid nutrient medium for $14 \mathrm{~h}$. Following incubation, the strain was spread onto BHIS solid nutrient supplemented with $10 \%$ sucrose. SacB gene from Bacillus subtilis encodes the enzyme levansucrase, which catalyzes sucrose hydrolysis and levan synthesis. C. glutamicum strains possessing a $s a c B$ gene is lethal in the presence of sucrose probably due to too much levan accumulating in periplasm of cells. (Jäger et al., 1992). And therefore only the double crossover homologous recombinants could survive on the sucrose-contaning medium. From these survivors, the $l d h A$ gene knockout recombinant GDK-9 $\Delta l d h A$ was isolated using primer pairs ldhA713-1 plus ldhA600-2 and upldh (5'-CAGGAGATGTTGGAGTTG-3') plus dpldh (5'-TTGAAGCGTTCCATCTCG-3').

\section{Fermentations}

For shake flask experiments, $30 \mathrm{~mL}$ culture broth in a $500 \mathrm{~mL}$ baffled flask was cultivated at $200 \mathrm{rpm}$ for $30 \mathrm{~h}$. When the initial glucose was depleted, the $500 \mathrm{~g} \mathrm{~L}^{-1}$ glucose solution was fed into the shake flask to keep the glucose concentration approximately at $20 \mathrm{~g} \mathrm{~L}^{-1}$. The $\mathrm{pH}$ was main- tained at 7.0 and controlled by the addition of $25.0 \%$ $\mathrm{NH}_{4} \mathrm{OH}$.

For L-glutamate fermentation, a 5-1 bioreactor (Shanghai Baoxing Bio-engineering Equipment co, Ltd) with an operating volume of 31 was used as fermenter. The seed cultures were grown for $8 \mathrm{~h}$ in shake-flasks $(100 \mathrm{~mL}$ seed medium inoculated into a 1-1 shake-flask, $200 \mathrm{rpm}, 32{ }^{\circ} \mathrm{C}$ ) to reach an $\mathrm{OD}_{600}$ about 12.0-16.0. Mature cultures were transferred to 3-1 production medium for L-glutamate production (inoculum size $10 \% \mathrm{v} / \mathrm{v}$ ), and cultivated for $24 \mathrm{~h}$. During the whole process, glucose concentration was maintained at approximately $20 \mathrm{~g} \mathrm{~L}^{-1}$ by adding $900 \mathrm{~g} \mathrm{~L}^{-1}$ glucose solution and the glucose feeding rate was adjusted according to glucose consumption rate of each hour. The $\mathrm{pH}$ was maintained at 7.0 and controlled by the addition of $25.0 \% \mathrm{NH}_{4} \mathrm{OH}$. DO concentration was maintained at $20 \%$ during the growth phase and was turned to $10 \%$ during glutamate-producing period. For assay of effect of DO on L-glutamate production by GDK-9 $\Delta l d h$, DO was adjusted as required by setting the agitation speed to a specified value (within the range 300 to $900 \mathrm{rpm}$ ) during glutamate-producing period. 


\section{Analysis methods}

During the fermentation process, $1 \mathrm{~mL}$ samples were taken from the cultures and centrifuged at $4{ }^{\circ} \mathrm{C}$ and 13,000 rpm for $5 \mathrm{~min}$. For biomass assay, dry cell weight was determined gravimetrically. Glucose concentration was determined with a biosensor (Institute of Biology, Shandong Academy of Science). Amino acids were analyzed as 2 , 4-fluoro-dinitrobenzene derivatives using high-performance liquid chromatography. Metabolites were detected by analytical methods as described previously (Kelle et al., 1996). Organic acids were screened by HPLC and an UV detector at $215 \mathrm{~nm}$ (HPLC, Series 1100, Agilent Technologies, USA, XDB-C8 column). HPLC was undertaken at $25^{\circ} \mathrm{C}$ and $\mathrm{pH} 3.0$, with $100 \mathrm{mM} \mathrm{L}^{-1} \mathrm{KH}_{2} \mathrm{PO}_{4}$ solution as mobile phase.

\section{Enzymatic assay for L-lactate dehydrogenase}

Bacterial cells were harvested and re-suspended in $50 \mathrm{mM}$ sodium phosphate buffer $(\mathrm{pH} 7.5)$ supplemented with $10 \mathrm{mM} \mathrm{MgCl}_{2}$, and grown to $20 \mathrm{OD}_{600}$ units. Cells were disrupted by sonication at $400 \mathrm{~W}$ for $10 \mathrm{~min}$ with $3 \mathrm{~s}$ pulse and 2 s pulse-off cycling (JY92-2D, SEIENTZ, Ningbo, China), followed by centrifugation at 8,000 rpm for $15 \mathrm{~min}$. The resulting supernatant was used as the cyto-soluble fraction. Total protein concentration in cell extracts was measured by Lowry's method (Sigma Kit) using bovine serum albumin as standard. Lactate dehydrogenase (LDH) assay was performed as previously described (Inui et al., 2004).

\section{Statistical analysis}

All experiments were conducted in triplicate, and data were averaged and presented as the mean \pm standard deviation (SD). One-way analysis of variance (ANOVA) followed by Dunnett's multiple comparison test were used to determine significant differences. Statistical significance was defined as $\mathrm{p}<0.05$.

\section{Results}

\section{Effect of IdhA gene deletion on L-glutamate production by GDK-9 in shake flask cultures}

To investigate the effect of $l d h A$ deletion on L-glutamate production by the L-glutamate- producing GDK-9, the gene was knocked out from the bacterium. Successful
IdhA deletion was validated by PCR and sequencing (data not shown). Moreover, measured enzymatic activity of LDH was $1.5 \mathrm{U} \mathrm{mg} \mathrm{protein}^{-1}$ in cell extract of the GDK-9, and negligible in GDK-9 $\Delta l d h$ (Table 2). These results further verified that the $l d h A$ gene had been successfully knocked out in GDK-9 $l d h A$.

Next, levels of L-glutamate, L-lactate and L-alanine produced by the $l d h A$-knockout strain GDK-9 $l d h A$ in shake flask (Table 2) were measured. Both strains yielded approximately the same biomass; however, L-glutamate production reached $70.4 \pm 1.33 \mathrm{~g} \mathrm{~L}^{-1}$ by GDK-9 $\Delta l d h A$, 9.15\% more than that attained by the GDK-9 $(64.5 \pm 1.91 \mathrm{~g}$ $\left.\mathrm{L}^{-1}\right)$ at $2630 \mathrm{~h}$. Moreover, the deletion of $l d h A$ resulted in a $97.6 \%$ and $44.6 \%$ decrease in L-lactate and L-alanine relative to the GDK-9, respectively. These data show that $l d h A$ gene deletion markedly improved L-glutamate production in GDK-9 and dramatically lower by-products formation.

\section{Effect of IdhA gene deletion on L-glutamate production by GDK-9 in fermenters}

To further examine the impact of the $l d h A$ deletion on L-glutamate production, we carried out 5-1 feed-batch fermentations using GDK-9 and GDK-9 $l d h$. Biomass, glucose concentration, and L-glutamate productions as functions of incubation time are presented in Figure 2. In early-stage cultures, the biomass of GDK-9 $\Delta l d h$ was slightly lower than that of the GDK-9. However, as the incubation time increased, both strains yielded similar biomass, indicating that $l d h A$ deletion did not adversely affect the growth of the bacteria. In addition, the glucose consumption rate of GDK-9 $l d h$ was slower than that of the GDK-9 during the growth phase, although this situation reversed when entering the stabilization growth phase. Despite these differences, the final L-glutamate titer reached $120 \mathrm{~g} \mathrm{~L}^{-1}$ by GDK-9 $\Delta l d h, 10.1 \%$ more than that of by GDK-9 (109 $\left.\mathrm{g} \mathrm{L}^{-1}\right)$ after $24 \mathrm{~h}$ of culture.

\section{Excretion of byproducts during fermentations}

During L-glutamate fermentation process, L-lactic acid, L-alanine and $\alpha$-ketoglutarate are the most common byproducts excreted into the medium (Jojima et al., 2010). To investigate the effect of $l d h A$ deletion on by-product production, concentrations of these three by-products were measured at the end of the fermentation process. As shown in Table 3, levels of L-lactic acid, L-alanine and $\alpha$-keto-

Table 2 - Concentration of L-glutamate, byproducts, and LDH specific activity, in shake flask studies of GDK-9 and GDK-9 $\Delta l d h A$.

\begin{tabular}{|c|c|c|c|c|c|}
\hline Strain & $\operatorname{DCW}\left(\mathrm{g} \mathrm{L}^{-1}\right)$ & L-glutamate $\left(\mathrm{g} \mathrm{L}^{-1}\right)$ & L-lactate $\left(\mathrm{g} \mathrm{L}^{-1}\right)$ & L-alanine $\left(\mathrm{g} \mathrm{L}^{-1}\right)$ & $\begin{array}{l}\text { LDH-specific activity } \\
(\mathrm{U} \mathrm{mg} \text { protein }\end{array}$ \\
\hline GDK-9 & $9.97 \pm 0.56$ & $64.5 \pm 1.33$ & $8.5 \pm 0.22$ & $1.95 \pm 0.05$ & 1.50 .06 \\
\hline GDK-9 $\Delta l d h A$ & $9.88 \pm 0.47$ & $70.4 \pm 1.91$ & $0.2 \pm 0.02$ & $1.08 \pm 0.04$ & $0.05 \pm 0.01$ \\
\hline
\end{tabular}

DCW: dry cell weight. Each datum represents the average value of at least three independent measurements. 

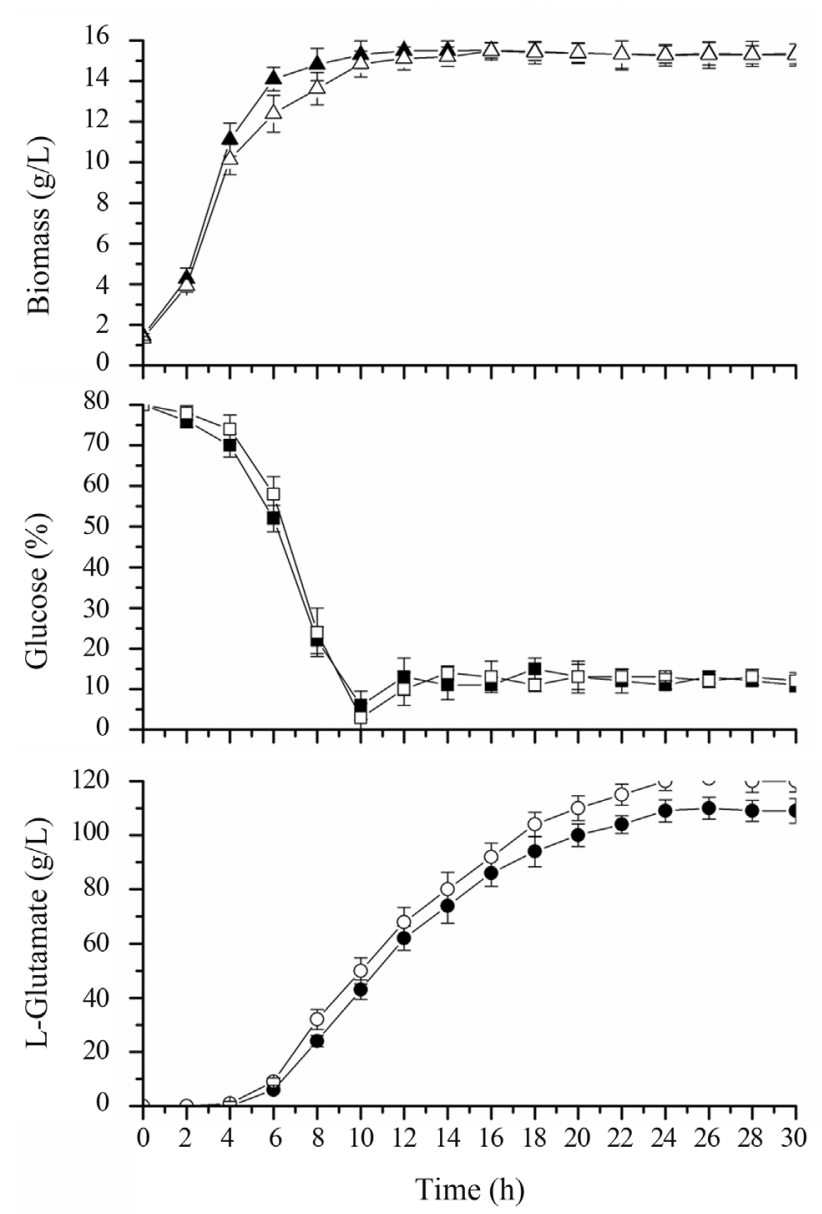

Figure 2 - Biomass, glucose and L-glutamate concentrations in glucose-controlled L-glutamate fed-batch fermentations of GDK-9 (solid symbols) and GDK-9 $\Delta l d h$ (open symbols).

glutarate secreted by GDK-9 $\Delta l d h$ were dramatically reduced relative to the wild-type $(97.1 \%, 50.91 \%$ and $20.45 \%$ reduction, respectively).

\section{Effect of the IdhA gene deletion on L-glutamate production by the GDK-9 under different DO conditions}

DO play an important role in L-glutamate production as well as by-products accumulation (Calik et al., 2001). To study the differences in performance between the $l d h A$ knockout strain and GDK-9 exposed to different DO levels, 5-1 fed-batch L-glutamate fermentations was performed under oxygen-deficient conditions ( $\mathrm{DO}=0 \%)$, micro-aerobic conditions $(\mathrm{DO}=10 \%)$ and high oxygen conditions $(\mathrm{DO}=30 \%)$ imposed at the L-glutamate production phase.

As shown in Figure 3, the biomass of both strains under oxygen-deficient conditions was slightly lower than that obtained under micro-aerobic and high oxygen conditions. Oxygen-deprived GDK-9 $\Delta l d h$ produced $4.04 \%$ more L-glutamate but $53.26 \%$ more L-alanine than GDK-9. While under micro-aerobic conditions, GDK-9 $\Delta l d h$ produced $11.6 \%$ more L-glutamate and 58.5\% less L-alanine than the GDK-9. However, under the high-oxygen condition, GDK-9 $\Delta l d h$ produced approximately $43.23 \%$ less L-alanine than the GDK-9, and produced similar amount of L-glutamate which is much lower than that produced under oxygen-deficient and micro-aerobic conditions. Collectively, these results show that deleting the $l d h A$ gene has little effect on L-glutamate production under oxygendeficient and high oxygen conditions, but exerts a pronounced effect under micro-aerobic conditions.

\section{Discussion}

From detailed studies of branched pyruvate metabolism, by-products have been pinpointed as the bottleneck for L-glutamate production in a high-yield strain (Uy et al., 2003). And it is suggested that molecular genetic manipula-

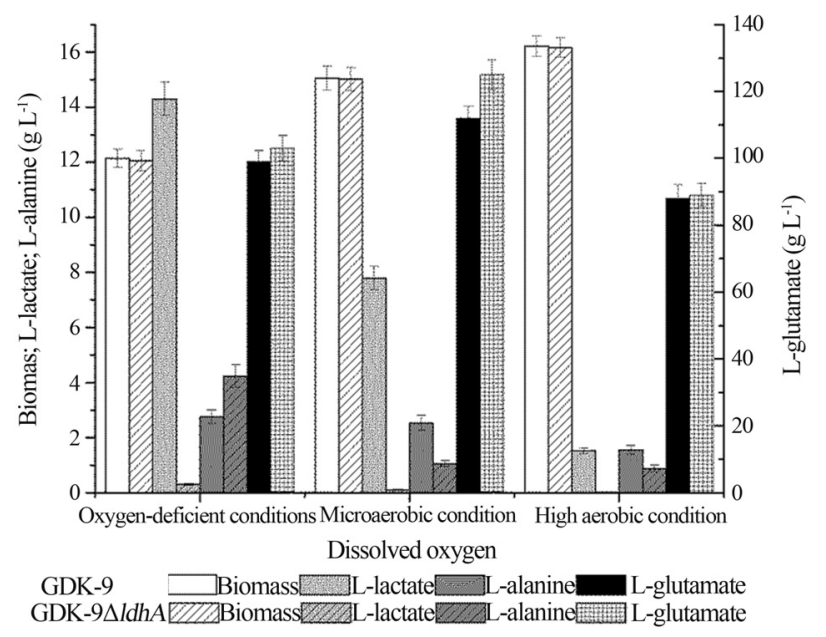

Figure 3 - Biomass gain, by-product and L-glutamate production under different dissolved oxygen conditions.

Table 3 - Concentration of byproducts in the medium at the end of the fermentation process.

\begin{tabular}{|c|c|c|c|}
\hline Strains & L-lactate $\left(\mathrm{g} \mathrm{L}^{-1}\right)$ & L-alanine $\left(\mathrm{g} \mathrm{L}^{-1}\right)$ & $\alpha$-ketoglutarate $\left(\mathrm{g} \mathrm{L}^{-1}\right)$ \\
\hline GDK-9 & $7.87 \pm 0.31$ & $2.12 \pm 0.18$ & $0.44 \pm 0.05$ \\
\hline GDK-9 $\Delta l d h A$ & $0.22 \pm 0.04$ & $1.04 \pm 0.15$ & $0.35 \pm 0.02$ \\
\hline
\end{tabular}

Each datum represents the average value of at least three independent measurements. 
tion and fermentation optimization are viable approaches to increasing the L-glutamate yield (Ikeda, 2003; Kirchnera et al., 2003). L-lactate and L-alanine are common by-products of glutamate production (Marienhagen et al., 2005). Minimizing the formation of such by-products is desirable in industrial-scale production of L-glutamate (Amin et al., 1993).

To enhance L-glutamate production, we here proposed to eliminate concurrent L-lactate formation by deleting the $l d h A$ gene encoding the NAD-dependent LDH enzyme, which is the sole L-lactate generating enzyme in C. glutamicum (Stansen et al., 2005). In this study, the ldhA gene was deleted from the L-glutamate-producing strain GDK-9. The GDK-9 $l d h$ produced more L-glutamate than the GDK-9 in shake-flask cultures, probably because this strain secreted less L-lactate (Table 2) and more metabolic flux was drawn to L-glutamate synthesis. As shown in Figure 2, the GDK-9 $l d h$ produced $10.1 \%$ more L-glutamate than the GDK-9 in 5-1 fed-batch fermentation studies, although the final biomass of the two strains was similar. Generally, a metabolically engineered microbe has a reduced growth rate compared to its parental strain (Jung et al., 2012). Studies report that $l d h A$ deletion in severals microbes reduced cell growth (Yang et al., 1999; Chen et al., 2009; Fiedler et al., 2011). Although the biomass of GDK$9 \Delta l d h$ was slightly lower than that of the GDK-9 in earlystage cultures, both strains yielded similar biomass as the incubation time increased, indicating that $l d h A$ deletion did not adversely affect the bacterial growth. However, the glucose consumption rate of the GDK-9 $\Delta l d h A$ was slightly slower than GDK-9 during the period of 2-6 h, which may be probably due to two reasons: on one hand, the biomass of GDK-9 $\Delta l d h A$ was smaller but both strains accumulated similar amount of glutamate in that period, thus less glucose was consumed; and on the other hand, metabolic flux from pyruvate to lactate was cut and therefore glucose wasted on lactate synthesis was prevented.

Throughout the fermentations, the main by-products excreted into the medium were L-lactic, L-alanine and $\alpha$-ketoglutarate. Compared with the GDK-9, the GDK$9 \Delta l d h A$ yielded lower levels of by-products (Tables 2 and 3). One possible explanation is that, in the GDK-9 $\Delta l d h A$, more pyruvate was fluxed to the TCA cycle for L-glutamate biosynthesis, leaving less carbon source for byproduct conversion.

The DO concentration has been shown to affect final L-glutamate production and the composition of extracellular amino acids produced (Zupke et al., 1995). In this study, the $l d h A$ deletion strain accumulated more L-alanine instead of L-lactate than the GDK-9 under oxygendeficient conditions. A possible explanation is that oxygen deprivation inhibits the TCA pathway (Cocaign-Bousquet et al., 1995). In this situation, pyruvate would accumulate, along with its derivatives L-alanine, L-lactate and ethanol.
And the deletion of the $l d h A$ gene from GDK-9 favors L-alanine accumulation. Here, we observed that deleting the $l d h A$ gene produced no obvious positive effect on L-glutamate production, possibly because the accumulated L-alanine inhibits L-glutamate synthesis under oxygendeficient conditions (Dominguez et al., 1993). We further demonstrated that L-alanine accumulation is reduced in GDK-9 $\Delta l d h$ relative to GDK-9 under micro-aerobic and high dissolved oxygen conditions.

It is reported that higher DO can strengthen TCA cycles but reduces activities of phosphoenolpyruvate carboxylase and glutamate dehydrogenase, and thus carbonfixation (supplying oxaloacetate to the TCA cycle) and glutamate synthesis were weaken (Gao et al., 2005; Yamamoto et al., 2011). And therefore L-glutamate concentration was higher under micro-aerobic conditions than under high aerobic conditions. Moreover, pyruvate carboxylase (PC) as another enzyme involved in oxaloacetate synthesis need biotin as its coenzyme. Hasegawa (2008) reported that PC activity under a biotin-limited condition was $\sim 20 \%$ of that under the condition with sufficient biotin. GDK-9 is a biotin-auxotroph strain and strategy used for this strain to trigger L-glutamate production is biotin limitation. As Figure 3 showed biomass of GDK-9 strains under high aerobic condition is higher and so more biotin was consumed than that under microaerobic condition and thus less PC activity was left. This is maybe another reason for the higher L-glutamate production under micro-aerobic conditions. These results indicate that the $l d h A$ mutant enhances L-glutamate production most effectively under micro-aerobic conditions.

It has been reported that increasing the activity of pyruvate dehydrogenase by over-expressing the respective genes or by introducing alleles for deregulated pyruvate dehydrogenase might improve L-glutamate production, and the reduced pyruvate dehydrogenase activity observed during L-glutamate production is purportedly responsible for by-product formation (Uy et al., 2003). Consequently, to further improve the already relatively efficient L-glutamate production in GDK-9, enhancing the activity of pyruvate dehydrogenase presents as a viable approach. Other promising approaches are optimization of fermentation technique and metabolic engineering. We have consolidated the validity of the latter approach in the results presented here.

\section{Acknowledgments}

We gratefully acknowledge the support from Jingbo Liang and Chunqian Guo. This work was supported by National Key Technology Research and Development Program of the Ministry of Science and Technology (2011BAC11B03), National High Technology Research and Development Program (2012AA02A703, 2013AA102106), Tianjin Municipal Science and Technol- 
ogy Commission (Grant No. 12ZCZDSY01900), and Program for Chang jiang Scholars and Innovative Research Team in University (IRT1166).

\section{References}

Akashi K, Shibai H, Hirose Y (1979) Effect of oxygen on L-phenylalanine, L-proline, L-glutamine and L-arginine fermentations. J Ferment Technol 57:317-320.

Amin G, Shahaby AF, Allah Khalaf, A.M (1993) Glutamic acid and by-product synthesis by immobilized cells of the bacterium Corynebacterium glutamicum. Biotechnol Lett 15:1123-1128.

Calik G, Unlutabak F, Ozdamar TH (2001) Product and by-product distributions in glutamic acid fermentation by Brevibacterium flavum: effects of the oxygen transfer. Biochem Eng $\mathrm{J}$ 9:91-101.

Cocaign-Bousquet M, Lindley ND (1995) Pyruvate overflow and carbon flux within the central metabolic pathways of Corynebacterium glutamicum during growth on lactate. Enzyme Microb Tech 17:260-267.

Dominguez H, Nezondet C, Lindley ND, Cocaign M (1993) Modified carbon flux during oxygen limited growth of Corynebacterium glutamicum and the consequences for amino acid overproduction. Biotechnol Lett 15:449-454.

Fiedler T, Bekker M, Jonsson M, Mehmeti I, Pritzschke A, Siemens N, Nes I, Hugenholtz J, Kreikemeyer B (2011) Characterization of three lactic acid bacteria and their isogenic $l d h$ deletion mutants shows optimization for YATP (cell mass produced per mole of ATP) at their physiological pHs. Appl Environ Microbiol 77:612-617.

Gao P, Lu JB, Duan ZY, Mao ZG, Shi ZP (2005) Effects of dissolved oxygen on the key enzymes in glutamate fermentation. Food Fermn Ind 31:72-75.

Grant SG, Jessee J, Bloom FR, Hanahan D (1990) Differential plasmid rescue from transgenic mouse DNAs into Escherichia coli methylation-restriction mutants. Proc Natl Acad Sci USA 87: 4645-4649.

Hasegawa T, Hashimoto K, Kawasaki H, NakamatsuT (2008) Changes in enzyme activities at the pyruvate node in glutamate-overproducing Corynebacterium glutamicum. J Biosci Bioeng 105:12-19.

Ikeda M (2003) Amino acid production processes. Adv Biochem Eng Biotechnol 79:1-35.

Inui M, Murakami S, Okino S, Kawaguchi $\mathrm{H}$, Vertès A, Yukawa $\mathrm{H}$ (2004) Metabolic analysis of Corynebacterium glutamicum during lactate and succinate productions under oxygen deprivation conditions. J Mol Microbiol Biotechnol 7:182-196.

Jäger W, Schäfer A, Pühler A, Labes G, Wohlleben W (1992) Expression of the Bacillus subtilis $s a c B$ gene leads to sucrose sensitivity in the gram-positive bacterium Corynebactenium glutamicum but not in Streptomyces lividans. J Bacteriol 174:5462-5465.

Jojima T, Fujii M, Mori E, Inui M, Yukawa H (2010) Engineering of sugar metabolism of Corynebacterium glutamicum for production of amino acid L-alanine under oxygen deprivation. Appl. Microbiol. Biotechnol 87:159-165.

Jung MY, Ng CY, Song H, Lee J, Oh MK (2012) Deletion of lactate dehydrogenase in Enterobacter aerogenes to enhance 2, 3-butanediol production. Appl Microbiol Biotechnol 95:461-469.
Keilhauer C, Eggeling L, Sahm H (1993). Isoleucine synthesis in Corynebacterium glutamicum: molecular analysis of the $i l v B-i l v N-i l v C$ operon. J Bacteriol 175:5595-5603.

Kelle R, Hermann T, Weuster-Botz D, Eggeling L, Kramer R, Wandrey C (1996) Glucose-controlled L-isoleucine fed-batch production with recombinant strains of Corynebacterium glutamicum. J Biotechnol 50:123-136.

Kirchnera O, Tauchb A (2003) Tools for genetic engineering in the amino acid-producing bacterium Corynebacterium glutamicum. J Biotechnol 104:287-299.

Marienhagen J, Kennerknecht N, Sahm H, Eggeling L (2005) Functional analysis of all aminotransferase proteins inferred from the genome sequence of Corynebacterium glutamicum. J Bacteriol 187: 7639-7646.

Chen N, Du J, Liu H, Xu Q (2009) Elementary mode analysis and metabolic flux analysis of L-glutamate biosynthesis by Corynebacterium glutamicum. Ann Microbiol 59:317-322.

Peters-Wendisch PG, Schiel B, Wendisch VF, Katsoulidis E, Mockel B, Sahm H, Eikmanns BJ (2001) Pyruvate carboxylase is a major bottleneck for glutamate and lysine production by Corynebacterium glutamicum. J Mol Microbiol Biotechnol 3:295-300.

Schäfer A, Tauch A, Jäger W, Kalinowski J, Thierbach G, Pühler A (1994) Small mobilizable multi-purpose cloning vectors derived from the Escherichia coli plasmids pK18 and pK19: selection of defined deletions in the chromosome of Corynebacterium glutamicum. Gene 145:69-73.

Stansen C, Uy D, Delaunay S, Eggeling L, Goergen J, Wendisch, VF (2005) Characterization of a Corynebacterium glutamicum lactate utilization operon induced during temperature-triggered glutamate production. Appl Environ Microb 71:5920-5928.

Takac S, Calik G, Mavituna F, Dervakos G (1998) Metabolic flux distribution for the optimized production of L-glutamate. Enzyme Microbial Technol 23:286-300.

Toyoda K, Teramoto H, Inui Masayuki, Yukawa H (2009) Molecular mechanism of SugR-mediated sugar-dependent expression of the $l d h A$ gene encoding L-lactate dehydrogenase in Corynebacterium glutamicum. Appl Microbiol Biotechnol 83:315-327.

Uy D, Delaunay S, Germain P, Engasser JM, Goergen JL (2003) Instability of glutamate production by Corynebacterium glutamicum 2262 in continuous culture using the temperature-triggered process. J. Biotechnol 104:173-184.

Van der Rest ME, Lange C, Molenaar D (1999) A heat shock following electro-poration induces highly efficient transformation of Corynebacterium glutamicum with xenogeneic plasmid DNA. Appl Microbiol Biotechnol 52:541-545.

Yang YT, San KY, Bennett GN (1999) Redistribution of metabolic fluxes in Escherichia coli with fermentative lactate dehydrogenase overexpressionand deletion. Metab Eng 1:141-152.

Yamamoto S, Sakai M, Inui M, Yukawa H (2011) Diversity of metabolic shift in response to oxygen deprivation in Corynebacterium glutamicum and its closerelatives. Appl Microbiol Biotechnol 90:1051-1061.

Zupke C, Sinskey AJ, Stephanopoulos G (1995) Intracellular flux analysis applied to the effect of dissolved oxygen on hybridomas. Appl Microbiol Biotechnol 44: 27-36.

All the content of the journal, except where otherwise noted, is licensed under a Creative Commons License CC BY-NC. 